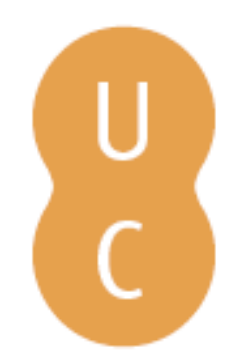

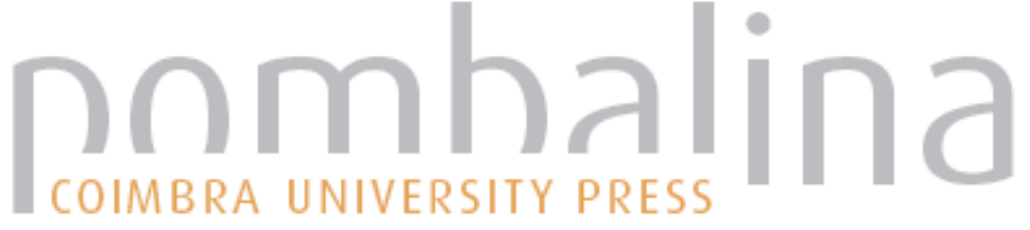

\section{Development of a spatial analysis tool for radiant heat flux predictions}
Autor(es):
Arena, Alessio; Leonard, Justin; Blanchi, Raphaele; Newnham, Glenn; Opie, Kimberley

Publicado por: Imprensa da Universidade de Coimbra

URL

persistente:

URI:http://hdl.handle.net/10316.2/44600

DOI:

DOI:https://doi.org/10.14195/978-989-26-16-506_83

Accessed : $\quad$ 26-Apr-2023 11:52:54

A navegação consulta e descarregamento dos títulos inseridos nas Bibliotecas Digitais UC Digitalis, UC Pombalina e UC Impactum, pressupõem a aceitação plena e sem reservas dos Termos e Condições de Uso destas Bibliotecas Digitais, disponíveis em https://digitalis.uc.pt/pt-pt/termos.

Conforme exposto nos referidos Termos e Condições de Uso, o descarregamento de títulos de acesso restrito requer uma licença válida de autorização devendo o utilizador aceder ao(s) documento(s) a partir de um endereço de IP da instituição detentora da supramencionada licença.

Ao utilizador é apenas permitido o descarregamento para uso pessoal, pelo que o emprego do(s) título(s) descarregado(s) para outro fim, designadamente comercial, carece de autorização do respetivo autor ou editor da obra.

Na medida em que todas as obras da UC Digitalis se encontram protegidas pelo Código do Direito de Autor e Direitos Conexos e demais legislação aplicável, toda a cópia, parcial ou total, deste documento, nos casos em que é legalmente admitida, deverá conter ou fazer-se acompanhar por este aviso.

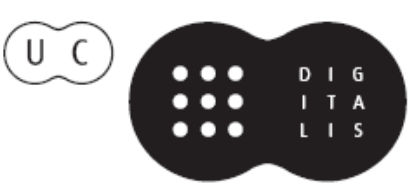




\section{ADVANCES IN}

\section{FOREST FIRE RESEARCH}

\section{8}

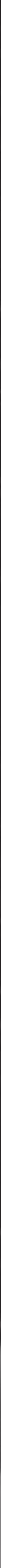




\title{
Development of a spatial analysis tool for radiant heat flux predictions
}

\author{
Alessio Arena*; Justin Leonard; Raphaele Blanchi; Glenn Newnham; Kimberley Opie \\ CSIRO Land and Water. \{alessio.arena@csiro.au*\}
}

\begin{abstract}
This paper describes a new tool developed to spatially quantify the radiant heat flux generated during a wildfire. Radiant heat generated by a wildfire can reach levels that are threatening for building structures and deadly for human life. Very dangerous situations can occur when fire shelters fail and people are required to change location. In Australia, radiant heat flux estimation has been used to model the potential exposure experienced by structures, and forms the basis for wildfire related building and planning regulations. The existing radiant heat estimation method was developed for on-site assessment, and tends to be simplistic and not scalable at a regional level. This can result in suboptimal design outcomes for builders and planners when implementing their fire risk management strategies. This paper describes a new spatial tool developed to better quantify maximum radiant heat flux at a local to regional scale. This tool builds on the estimation method already in use within the Australian legislation, improving its efficiency and expanding its spatial capabilities. The result is a comprehensive radiant heat map that can improve our understanding of conditions during wildfire as a means of understanding mechanisms for human impacts and structure loss.
\end{abstract}

Keywords: radiant heat flux, spatial, GIS, fire, risk

\section{Introduction}

Wildfires are one of the most dangerous natural hazards in Australia, impacting hundreds of properties and lives each year. Ember attack is the main cause of house and property loss (Blanchi and Leonard 2008), while radiant heat transfer poses the highest threat to firefighters and building occupants in cases of emergency shelter evacuation (Butler and Cohen 1998; Cheney et al. 2001; Whittaker et al. 2017).

The threat from radiant heat transfer needs to be accounted for at many levels of planning, including urban and emergency planning, and in building standards (Cohen 1995; Butler and Cohen 1998; Siggins et al. 2013; Newnham et al. 2014). This has lead to the development of the Australian Standards AS3959 (Standards Australia 2009) which outlines the official methodology to calculate the radiant heat flux (RHF) a person or structure could be exposed to in the 'worst case' scenario wildfire.

This standards document is currently used by all government organisations to guide many of their decisions regarding wildfires, including new development approvals and emergency planning. However, the methodology outlined in AS3959 was developed for field assessments of wildfire risk at local scale and is difficult to apply at a larger scale.

This paper outlines an adaptation of the AS3959 methodology through development of a spatial tool to allow assessment at local to regional scales. This tool was developed in Python 2.7 leveraging the ArcGIS platform to allow user friendly interaction and adaptation of relevant RHF modelling parameters.

\section{Background}

In this section we outline the state-of-the-art methods to quantify the RHF for a wildfire in Australia. This information is available in Sullivan, Ellis, \& Knight, 2003 and Standards Australia, 2009. 


\subsection{Radiant heat flux model for wildfires}

Radiation is one of the three mechanisms of heat transfer from a flame body, the others being conduction and convection. The Stefan-Boltzmann equation for a real surface defines the maximum amount of heat transferred in this way:

$$
q=\varepsilon \sigma T^{4}
$$

where $\sigma$ is the Stefan-Boltzmann constant of value $5.67 * 10^{-8} \mathrm{Wm}^{-2} \mathrm{~K}^{-4}, T$ is the absolute temperature of the radiating surface $(\mathrm{K}), \varepsilon$ is the emissive power of the surface as a ratio of total radiation emitted by the surface to that emitted by a blackbody of the same temperature, and $q$ is the emissive power per unit area $\left(\mathrm{Wm}^{-2}\right)$.

The efficiency of this mechanism is largely affected by the relative position of source and receiver, often referred to as "view factor" (Sullivan et al. 2003). This leads to the equation:

$$
E=\phi \varepsilon \sigma T^{4}
$$

where $\varphi$ is the view factor, and $E$ is the RHF received at the surface.

Additionally, the geometry of the source surface greatly affects the directional distribution of the emissions and the corresponding flux. In fact, a unit surface area radiates in all directions such that the intensity is proportional to the cosine of the angle between the direction and the normal to the surface. In the case of a wildfire front, the geometry of the radiating body is often approximated to an opaque box. Flame width, flame height and flame angle to the vertical are used to describe the geometry of the opaque box, and are important inputs for the RHF model (Sullivan et al. 2003).

\subsection{Bushfire Attack Level (BAL) assessment}

The AS3959 uses simplified radiant heat transfer estimation methods derived from Sullivan et al. 2003 and aims to capture the worst case scenario of a wildfire given information including available fuel, landscape characteristics and weather conditions. The resulting worst case RHF is then converted into a BAL using threshold values summarised in Table. Each increasing BAL increment requires increasing wildfire protection measures to meet the AS3959 requirements.

Table 1 - Summary of Bushfire Attack Levels with associated conditions and main risk factors (from Standards Australia 2009)

\begin{tabular}{|c|c|c|}
\hline $\begin{array}{c}\text { Bushfire Attack Level } \\
\text { (BAL) }\end{array}$ & Condition & Main risk factors \\
\hline BAL-LOW & Distance $>100 \mathrm{~m}$ & Insufficient risk \\
\hline BAL-12.5 & $\mathrm{RHF} \leq 12.5 \mathrm{~kW} / \mathrm{m}^{2}$ & Ember attack \\
\hline BAL-19 & $\begin{array}{c}12.5 \mathrm{~kW} / \mathrm{m}^{2}>\mathrm{RHF} \geq 19 \\
\mathrm{~kW} / \mathrm{m}^{2}\end{array}$ & $\begin{array}{c}\text { Ember attack and radiant } \\
\text { heat }\end{array}$ \\
\hline BAL-29 & $\begin{array}{c}19 \mathrm{~kW} / \mathrm{m}^{2}>\mathrm{RHF} \geq 29 \\
\mathrm{~kW} / \mathrm{m}^{2}\end{array}$ & $\begin{array}{c}\text { Ember attack and radiant } \\
\text { heat }\end{array}$ \\
\hline BAL-40 & $\begin{array}{c}29 \mathrm{~kW} / \mathrm{m}^{2}>\mathrm{RHF} \geq 40 \\
\mathrm{~kW} / \mathrm{m}^{2}\end{array}$ & $\begin{array}{c}\text { Ember attack, radiant heat } \\
\text { and direct flame interaction }\end{array}$ \\
\hline BAL-FZ & $\mathrm{RHF}>40 \mathrm{~kW} / \mathrm{m}^{2}$ & Direct flame interaction \\
\hline
\end{tabular}

The BAL assessment is performed in the field by trained personnel. Due to the complexity of the calculation, AS3959 (2009) includes a simplified 'method 1' using precomputed values in a tabulated form. This method is limited to a very small set of input values (e.g. slope increments of 5 degrees, only distances for the BAL transitions), and returns only the corresponding BAL bracket. 
The underlying 'method 2' is also provided. This is a complete calculation method, and can be generally outlined:

1. Determine the weather parameters to use as reference (typically Fire Danger Index, or FDI)

2. Determine the vegetation classification, fuel loads and characteristics

3. Determine the effective slope under the vegetation, which is the slope corresponding to the fire spread direction

4. Determine the slope of the land between the site assessed and the vegetation

5. Determine the distance between site and vegetation

6. Calculate the flame length using the rate of spread (RS) modified for the effective slope and the vegetation and weather conditions

7. Determine the flame width

8. Determine the elevation of the receiver

9. Calculate the radiant heat flux corresponding to the worst possible flame angle and resulting view factor. This is an iterative step to find the maximum value

10. Determine the BAL

Rate of fire spread for each vegetation type is calculated using empirical formulas (described in Catchpole et al., 1998; Marsdens-medley \& Catchpole, 1995; Noble, Gill, \& Bary, 1980). These formulae consider vegetation type and condition, landscape morphology and weather conditions, which are approximated into broad classifications, empirical formulas or indices. Additionally, this methodology does not consider barriers or actual visibility of the vegetation from the site. These parameters are difficult to assess during field assessment, and are therefore considered out-of-scope for

\section{Spatial calculation of radiant heat flux using AS3959 (2009) method 2}

The development of a more accurate, landscape-scale calculation of RHF requires implementation of AS3959 (2009) method 2 in a Geographic Information System (GIS) environment. Our key considerations during the development of this tool were:

- spatial scalability to address local to regional scenarios,

- performance, due to the often limited resources available using desktop GIS platforms, and

- minimal input requirement, to minimise the requirement for precomputed data, and facilitate the use of readily available and generic datasets.

\subsection{Input datasets}

GIS environments support two families of spatial datasets: raster datasets, which are comprised of discrete spatial units such as the pixels in a typical satellite image, and vector datasets which contain points, lines and features. Many publicly available large-scale datasets are rasters derived from remote sensing, including vegetation classification datasets (e.g. Ecological Vegetation Class in Victoria) that can be used to estimate fire fuel characteristics.

The typical resolution of remote-sensing derived rasters is too coarse for detailed risk analyses. To better model spatial variability, this tool requires the user to provide a more detailed vector file containing polygons of the vegetation footprint to accurately map vegetation boundaries. The input datasets required are: 
- vegetation polygons (vector), with attached vegetation type, surface fuel load and total fuel load;

- $\quad$ site polygons or centroids (vector), to determine the processing extent or region of interest (ROI);

- digital elevation model (raster), with its derived

$\circ$ terrain slope (raster) and

$\bigcirc$ terrain aspect (raster)

- weather conditions, like fire danger index, wind speed and moisture factor.

Some of these parameters may be optional depending on the vegetation type (Standards Australia, 2009, table B1).

\subsection{Implementation}

The current implementation uses two outer loops, the first to iterate through buildings. This is used to set the Region of Interest (ROI), allowing optimisation of memory usage while being able to handle very large input datasets. At the same time, the building dataset is optional and can be omitted if a region-wise calculation is required. In this case, the processing extent will need to be set before running the tool.

The second loop iterates through vegetation polygons included within the ROI. Each of those polygons is treated as an independent source and used to calculate a RHF raster. Once all the vegetation polygons have been processed, the RHF rasters are combined to keep the maximum value for each pixel.

The calculation within the second loop is linearly structured:

1. Calculate the Euclidean distance and direction from the vegetation. The distance will be a direct input for the RHF calculation.

2. Using the Euclidean allocation algorithm, calculate the elevation, slope and aspect for the closest vegetation at any point in space (Euclidean elevation, Euclidean slope and Euclidean aspect).

3. Convert the Euclidean slope to effective slope, which is the slope a person would experience at that location by walking in the direction of the receiver. This is often referred in other disciplines as 'projected slope', 'actual slope' or 'directional slope', and is computed by:

a. Calculating the vector product between Euclidean aspect (direction where the slope underneath the vegetation is facing towards) and Euclidean direction (direction towards the receiver).

b. This product is then multiplied to the Euclidean slope.

4. Calculate the slope between source and receiver using the elevation at both points, as defined in Standards Australia, 2009.

5. Perform the RHF calculation using method 2 (Standards Australia 2009) at any point in space. Inputs are effective slope underneath the vegetation, slope between site and vegetation, distance to vegetation, vegetation and weather conditions.

A diagram of the RHF calculation steps is provided in Figure 1. 


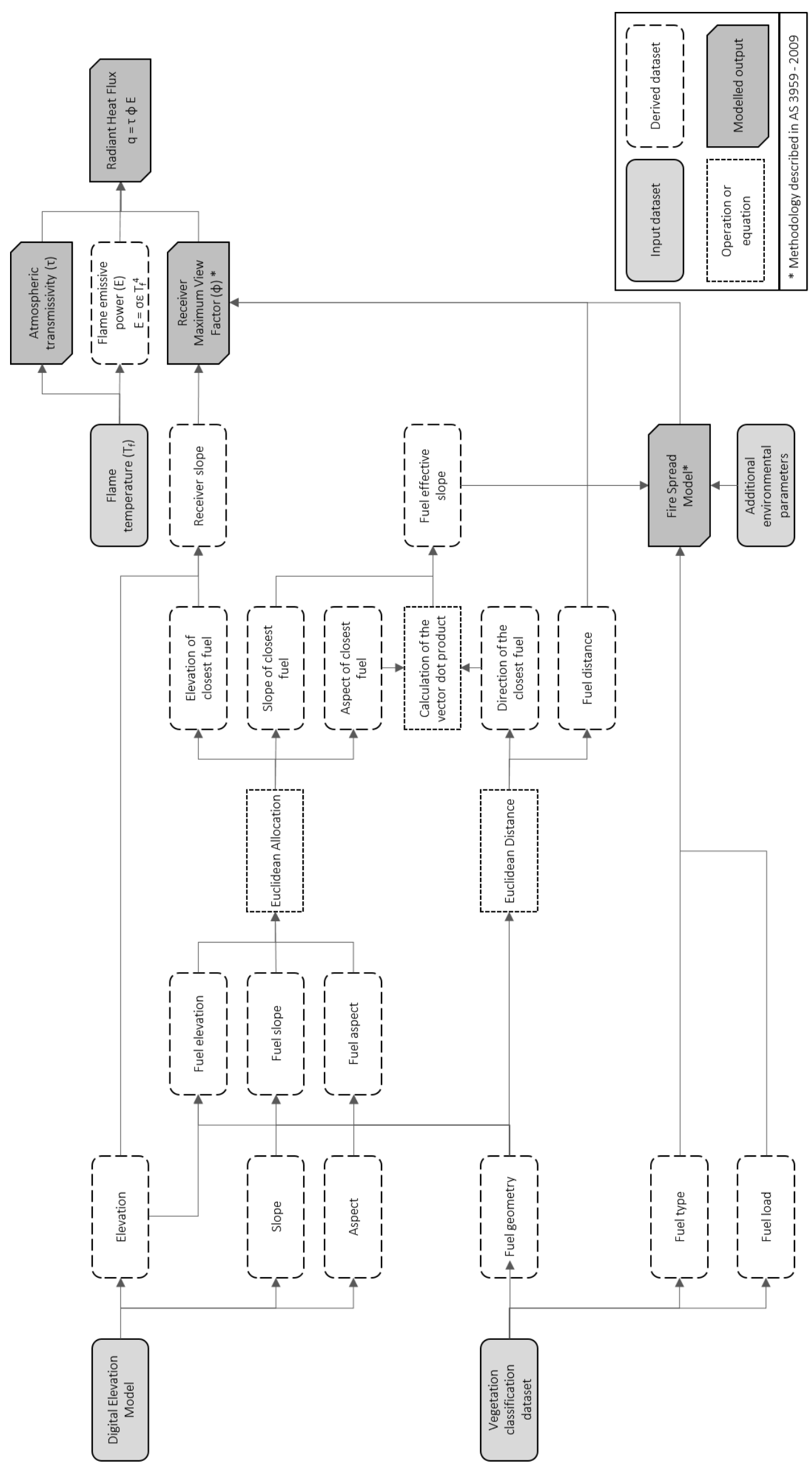

Figure 1 - Diagram representing the workflow used to calculate the radiant heat flux 


\subsection{Current limitations}

This implementation of the GIS tool calculates the RHF at any point in space using characteristics of the closest fuel. This approach allows to leverage the Euclidean distance algorithm, and efficiently calculate RHF at any location. However, the highest RHF may not be generated by the closest fuel as vegetation characteristics can have a much higher impact. Consequently, this approach will underestimate RHF values where characteristics of the closest fuel are in fact not the worst that location is exposed to. The resulting artefact will appear as a sharp change in RHF values

The use of iterations through each vegetation polygon allowed us to account for most vegetation characteristics. Each polygon is treated as an independent source and generates an intermediate RHF map. Those maps are then combined to keep only the highest RHF value given by the most dangerous vegetation polygon. However, the slope underneath vegetation can vary greatly within the same polygon, and cannot be fully accounted for by our approach.

Below is an example of the artefact we described, caused by the concave shape of the vegetation polygon that results in a large variation in effective slope.

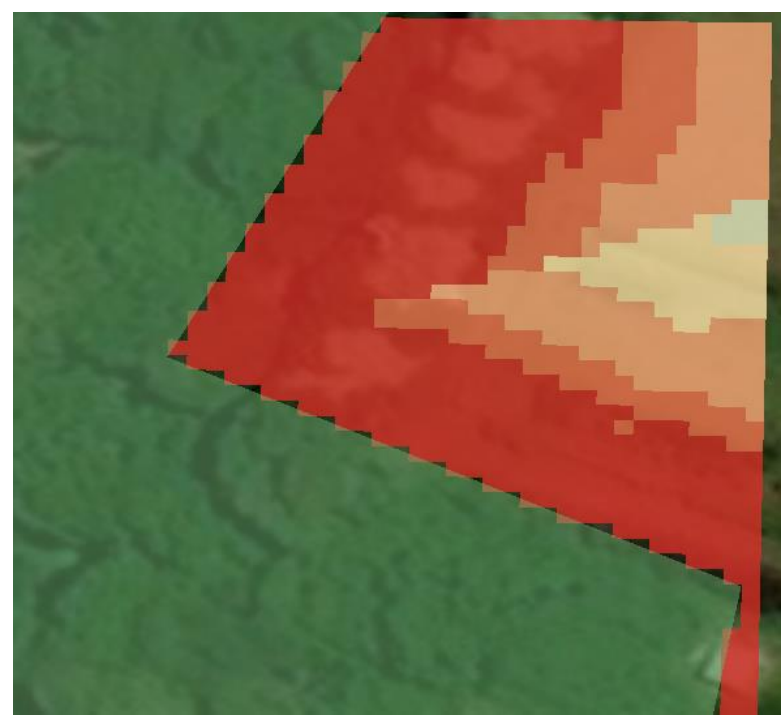

Figure 2 - Example of artefact due to the Euclidean distance based approach (top right corner). In green is the vegetation, and in red to yellow are the decreasing BAL from BAL-FZ to BAL12.5

\section{Results and discussion}

This tool was successfully used to produce RHF maps for 60 buildings in a case study in Victoria, to assess the relative safety of community shelters and associated offsite assembly areas in case of a wildfire. This involved assessing the likelihood of survival of the structure and the radiant heat that occupants may be exposed to during the evacuation.

This case study included vegetation information for 200 polygons over an area of 960 hectares and generating results for approximately 3.3 million locations. This analysis was completed in approximately $1.5 \mathrm{~h}$ using a moderately high specification commercially available workstation.

RHF values produced in this way were in agreement with manual calculations using both method 2 and method 1 AS3959 (2009). An example map is available in Figure . 

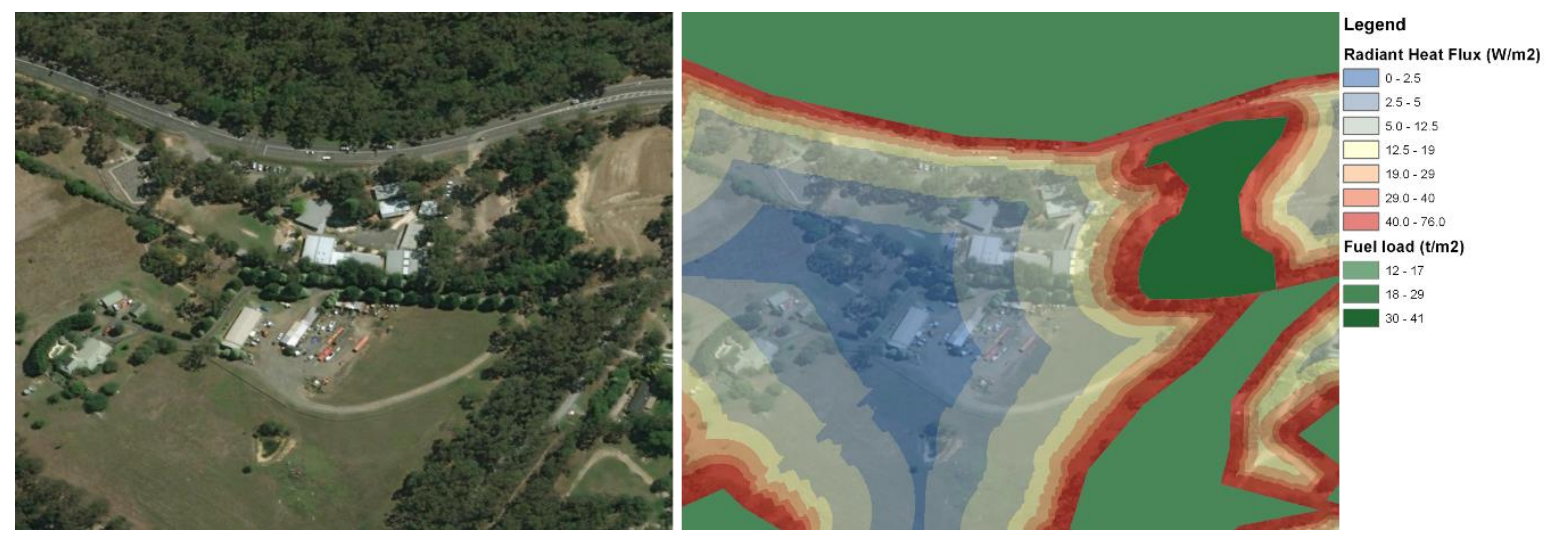

Figure 3 - Example RHF map from the case study. The area in light blue $\left(<2.5 \mathrm{~kW} / \mathrm{m}^{2}\right)$ is considered to be safe for humans without protective clothing

In comparison to a typical field assessment, the output maps derived from the tool provide a more comprehensive view of the risks that wildfire may pose to the assessed site.

This tool has the potential to be used to:

- Increase the objectivity of RHF assessments compared to the typical field assessment methods

- Assist in identifying safer emergency evacuation points that consider vegetation and terrain conditions over a larger spatial region

- Inform the definition of preferred evacuation paths for use during emergency events

This tool does not account for occlusion of the radiating source from the receiver in cases where there are opaque barriers (e.g. other buildings, fences) or complex topography. The underlying method used to perform the calculation (method 2 AS3959 (2009)) does not address this issue.

For this reason a more sophisticated approach using a ray-casting algorithm is currently under development (Leonard et al. 2014, 2015; Hilton et al. 2017). This will likely produce a more realistic radiant heat flux profile but will require a very accurate $3 \mathrm{D}$ scene of the site.

\section{Conclusion}

The methodology described in this paper is a valid alternative to single point-based estimates for radiant heat flux, while still conforming to the current Australian legislation. These estimates are often carried in the field at a single location and rely on the simplified 'method 1' provided by AS3959 (Standards Australia 2009). This new approach is based on the more accurate 'method 2' from AS3959 but provides a simple way to extend this method to analysis of not just a single house.

The developed tool uses readily available datasets and information to generate radiant heat maps in an objective and repeatable way. The tool proves to be computationally efficient and can be effectively used with all modern hardware configurations.

The output generated is also spatially aware, providing a more comprehensive understanding of hazard level at the landscape scale during a wildfire. This spatial context provides additional insights that can help in making more informed bushfire management decisions, such as better planning for safe sheltering and egress during fire events.

\section{References}

Blanchi R, Leonard J (2008) Property safety: judging structural safety. 'Community Bushfire Saf.' (Eds J Handmer, K Haynes) pp. 77-85 
Bradstock RA, Mccarthy G, Mccaw L (1998) Cooperative development of equations for heathland fire behaviour. https://www.researchgate.net/publication/299193502.

Butler BW, Cohen JD (1998) Firefighter Safety Zones: A Theoretical Model Based on Radiative

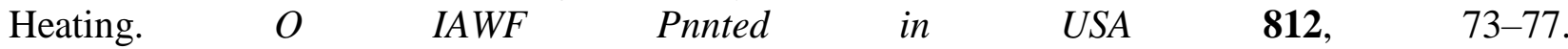
http://citeseerx.ist.psu.edu/viewdoc/download?doi=10.1.1.369.4565\&rep=rep1\&type=pdf.

Cheney P, Gould J, McCaw L (2001) The dead-man zone - a neglected area of firefighter safety. Australian Forestry 64, 45-50.

Cohen JD (1995) Structure ignition assessment model (SIAM) (DR Weise and RF Martin, Eds.). Biswell Symp. fire issues Solut. urban interface Wildl. Ecosyst. 85-92.

Hilton JE, Leonard J, Blanchi R, Newnham G, Opie K, Rucinski C, Swedosh W (2017) Dynamic modelling of radiant heat from wildfires. In 'MODSIM 2017', 1104-1110 https://www.mssanz.org.au/modsim2017/H10/hilton.pdf.

Leonard J, Newnham G, Opie K (2015) Silvan Water Treatment Plant - Fire Risk Assessment. CSIRO, https://publications.csiro.au/rpr/pub?list=SEA\&pid=csiro:EP155256\&sb=RECENT\&expert=false $\& n=2 \& \mathrm{rpp}=25 \&$ page $=1 \& \operatorname{tr}=22 \& \mathrm{q}=$ radiant heat $\& \mathrm{dr}=\mathrm{all}$.

Leonard J, Newnham G, Opie K, Blanchi R (2014) Millgrove Community FireRefuge - Site AssessmentJuly 2014. https://publications.csiro.au/rpr/pub?list=SEA\&pid=csiro:EP1410452\&sb=RECENT\&expert=fals $\mathrm{e} \& \mathrm{n}=5 \& \mathrm{rpp}=25 \&$ page $=1 \& \mathrm{tr}=22 \& \mathrm{q}=$ radiant heat $\& \mathrm{dr}=\mathrm{all}$.

Marsdens-medley J, Catchpole W (1995) Fire Behaviour Modelling in Tasmanian Buttongrass Moorlands .II. Fire Behaviour. International Journal of Wildland Fire 5, 215. doi:10.1071/WF9950215.

Newnham G, Blanchi R, Leonard J, Opie K, Siggins A (2014) Bushfire Decision Support Toolbox Radiant Heat Flux Modelling: Case Study Three, 2013 Springwood Fire, New South Wales. (Melbourne)

NOBLE IR, GILL AM, BARY GA V. (1980) McArthur's fire-danger meters expressed as equations. Austral Ecology 5, 201-203. doi:10.1111/j.1442-9993.1980.tb01243.x.

Siggins A, Newnham G, Blanchi R, Leonard J (2013) A 3 Dimensional ray tracing approach to modelling bushfire radiant heat flux for house using lidar derived vegetation voxel data and quadratic polygonal fire fronts. IEEE Int. Geosci. Remote Sens. Symp.

Standards Australia (2009) 'AS3959 - Construction of buildings in bushfire prone areas.' (Standards Australia: Sydney) http://www.royalcommission.vic.gov.au/getdoc/2d486ba8-2cef-45a1-9f3c6e058ec8a78a/WIT.3000.002.0108.PDF.

Sullivan AL, Ellis PF, Knight IK (2003) A review of radiant heat flux models used in bushfire applications. International Journal of Wildland Fire 12, 101. doi:10.1071/WF02052.

Whittaker J, Blanchi R, Haynes K, Leonard J, Opie K (2017) Experiences of sheltering during the Black Saturday bushfires: Implications for policy and research. International Journal of Disaster Risk Reduction 23, 119-127. doi:10.1016/j.ijdrr.2017.05.002. 